EDITORIAL

\title{
The changing state of surgery for adult congenital heart disease
}

J Monro

Heart 2005;91:139-140. doi: 10.1136/hrt.2004.039057

The number of patients with adult congenital heart disease is expected to increase by $25 \%$ during this decade, so that by 2010 there will be more patients undergoing surgery for congenital heart disease over 16 years of age than under

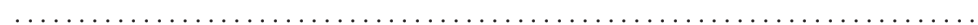

A $s$ a result of the ever increasing success of paediatric cardiac surgery, there is a steadily growing number of adults with congenital heart disease. In addition to those who have survived surgery, there are many patients over the age of 16 years with congenital heart disease who have not had surgery, either because they do not need it, or because it has been discovered late. Although we have been aware of these patients for a long time, it was really Jane Somerville ${ }^{1}$ who drew our attention to their needs, calling them GUCH (grown up congenital heart disease). The name seems to have stuck, even though we might prefer to be called adults rather than grown ups!

GUCH patients have special needs, and particularly the transition from the paediatric to the adult setting needs careful handling. Their management should be undertaken by doctors and nurses familiar with their needs and most will require regular follow up for life. The outpatient clinics need adequate staff and facilities, in particular, good echocardiographic equipment. When they are admitted to hospital, they should preferably be in a suitable ward for young adults and in hospitals familiar with their management. The report of the British Cardiac Society working party ${ }^{2}$ suggested only 4-6 such units in the UK and certainly centralisation, so that each unit has an adequate number of patients to manage, is sensible.

\section{SURGERY FOR GUCH PATIENTS}

At the moment in the UK, the surgeons from the paediatric only units are having to undertake surgery for GUCH patients at nearby adult hospitals, whereas in mixed units, the same team may follow the patient from infancy well into adulthood in the same hospital. This latter situation obviously has merit, but inevitably a compromise exists at the moment. ${ }^{3}$

Each year a proportion of GUCH patients need surgery. In this issue of Heart, Srinathan and colleagues $^{4}$ from Birmingham (UK) describe their experience from January 1990 to December 2002, which they divide into three equal 52 month periods. Although the number of GUCH patients being operated on in each period is about the same, the proportion of simple cases declined from $46 \%$ in the first period to $28 \%$ in the last period, and the percentage of redo operations went up from $25 \%$ to $50 \%$. Despite the patients becoming more complex, the operative mortality remained much the same, hospital and intensive therapy unit (ITU) stay was short, and blood usage did not increase. The overall early mortality was $6.3 \%$, which fell to the impressive figure of $3.4 \%$ for the last period.

The proportion of patients having atrial septal defect (ASD) closure fell significantly, because of the increased use of interventional device closure by the cardiologists. Despite the reduction in surgical ASD closure, the overall numbers in each period have remained fairly constant, presumably because more survivors are requiring further surgery. In addition to ASD closure, the cardiologists are ballooning and stenting narrowed pulmonary arteries and coarctations of the aorta. Whereas these procedures are obviously less invasive for the patient than traditional surgery, there are situations where surgery is more appropriate, and a sensible team approach with discussion is best. Sometimes a combined surgical and cardiological approach is appropriate, for example, placing a pulmonary artery stent in a narrowed pulmonary artery at the time of surgery.

Although the report from Birmingham shows a similar number of operations on GUCH patients in each period, this may be slightly misleading as theirs is a somewhat atypical experience. Before the appointment of two excellent surgeons to the Birmingham Children's Hospital in the late 80s, the results, particularly in infants, were poor. The Kennedy Inquiry following the Bristol report revealed that as reported by the UK Surgical Register, in the period 1982-85 Birmingham had the highest infant mortality in the country with 39\%, whereas in the period 1992-95 they had the lowest infant mortality in the country with $9 \%{ }^{5}$ Therefore fewer survivors were coming through to the period of this report in Birmingham than might have been expected elsewhere. In addition, the quality of the initial repair is likely to affect the need for further surgery. ${ }^{6}$ However good the initial repair, patients having certain procedures (for example, valve repair and operations requiring conduit insertion) will almost inevitably require further surgery. Therefore for many years it has been appreciated that in most

Abbreviations: ASD, atrial septal defect; $\mathrm{GUCH}$, grown up congenital heart disease; HLHS, hypoplastic left heart syndrome; TCPC, total cavopulmonary connection 
cases the initial operation is a "repair" rather than a "correction".

\section{CONDUIT REPLACEMENT}

In the case of conduit replacement, most surgeons would use a homograft for right ventricle to pulmonary artery continuity. It is well known that they tend to calcify in time, leading to narrowing and valvar incompetence, with the inevitable strain on the right ventricle. Similarly patients who have had initial repair of tetralogy of Fallot with a transannular patch will develop increasing pulmonary regurgitation and require insertion of a valve into the right ventricular outflow tract. Sadly the cryopreserved homografts available today do not seem to be lasting as long as those kept at $4{ }^{\circ} \mathrm{C}$ following antibiotic sterilisation, ${ }^{7}$ some of which have lasted more than 20 years. ${ }^{8}$ Therefore, unless a return is made to the original preparation and storage methods, it is likely that the proportion of GUCH patients having right ventricular outflow surgery will increase further. The more recently introduced bovine jugular vein conduit seems promising, but the follow up is too short to be confident of its long term performance.

Most patients having Fontan procedures performed in the 1980s had a direct right atrium to pulmonary artery anastomosis. Many of these patients are now deteriorating with arrhythmias and large right atria. Redo surgery with an extra cardiac conduit, right atrial downsizing, and cryoablation $^{9}$ is proving successful in many. Some may require transplantation but this is not a good long term solution. The introduction of the total cavopulmonary connection (TCPC), ${ }^{10}$ and subsequent extracardiac conduit, have improved the outcome of these "Fontan" patients so much that hopefully when the backlog of previous patients has been dealt with there will be fewer patients requiring further surgery. This may be offset by the patients with hypoplastic left heart syndrome (HLHS) whose right ventricles are unlikely to do so well long term, and for whom transplantation may be the only eventual option.

The number of patients with adult congenital heart disease in the UK in 2000 was about 132000 and it is calculated that by 2010 there will be 165000 (a 25\% increase). ${ }^{11}$ By that time it is likely that there will be more patients undergoing surgery for congenital heart disease over 16 years of age than under. It is therefore important that we have good data to know where these operations are performed and by whom, and the results. In England the collection of data on patients undergoing surgery for congenital heart disease has, in the last few years, been undertaken by the Central Cardiac Audit Database (CCAD) and the validated results in children for 2000-2001 were recently reported. ${ }^{12}$ Unfortunately the results in patients having operations for congenital heart disease over the age of 16 has rather fallen between CCAD and the
National Adult Cardiac Surgical Database organised by Bruce Keogh. ${ }^{13}$ This is an important area in which data are needed, and this shortfall needs to be addressed.

\section{DATA COLLECTION}

There needs to be a specific collection of data on all patients over 16 years operated on for congenital heart disease. As suggested by Srinathan and colleagues ${ }^{4}$ it is probably best to exclude first time aortic valve surgery and Marfan's syndrome. However, all other operations should be recorded, including where they were performed and by whom. Although it is likely that adult surgeons will continue to close ASDs, more complex surgery such as insertion of conduits into the right ventricular outflow tract should be done by surgeons trained in congenital heart surgery.

In conclusion, it can be said that surgery for adult patients with congenital heart disease is increasing and becoming more complex with more redo operations. Despite this, excellent results can be achieved but good data collection is needed, with monitoring of where this surgery is performed.

\section{REFERENCES}

1 Somerville J. Management of adults with congenital heart disease: an increasing problem. Annu Rev Med 1997;48:283-93.

2 Somerville J. Grown up congenital heart (GUCH) disease: current needs and provisions of service for adolescents and adults with congenital heart disease in the UK. Heart 2002;88(suppl 1):i1-14.

3 Department of Health. Paediatric and congenital cardiac services review. Department of Health Report, 2002. www.advisorybodies.doh.gov.uk/ childcare/index.htm.

4 Srinathan SK, Bonser RS, Sethia B, et al. Changing practice of cardiac surgery in adult patients with congenital heart disease. Heart 2005;91:207-12.

5 Anon. Report of the public inquiry into children's heart surgery at the Bristol Royal Infirmary 1984-1995. www.bristol-inquiry.org.uk.

6 Monro JL, Alexiou C, Salmon AP, et al. Reoperations and survival after primary repair of congenital heart defects in children. J Thorac Cardiovasc Surg 2003;126:511-20.

7 Forbess JM, Shah AS, St Louis JD, et al. Cryopreserved homografts in the pulmonary position: determinants of durability. Ann Thorac Surg 2001;71:54-60.

8 Alexiou C, Keeton BR, Salmon AP, et al. Repair of truncus arteriosus in early infancy with antibiotic sterilised aortic homografts. Ann Thorac Surg 2001 May;7(suppl 5):S371-4.

9 Mavroudis C, Backer CL, Deal BJ, et al. Total cardiopulmonary conversion and maze procedure for patients with failure of Fontan operation. J Thorac Cardiovasc Surg 2001;122:863-71.

10 de leval MR, Kilner $P$, Gewillig $M$, et al. Total cavopulmonary connection: a logical alternative to atriopulmonary connection for complex Fontan operations-experimental studies and early clinical experience. J Thorac Cardiovasc Surg 1988;96:682-95.

11 Hall R. Fifth report on the provision of services for patients with heart disease. Heart 2002;99(suppl III):iii36-37.

12 Gibbs JL, Monro JL, Cunningham D, et al. Survival after surgery or therapeutic catheterisation for congenital heart disease in children in the United Kingdom: analysis of the Central Cardiac Audit Database for 2000-1. BMJ 2004;328:611-15.

13 Keogh BE, Kinsman R. National adult cardiac surgical database report 200001. UK: Dendrite Clinical Systems, 2002. 